\title{
Paget's disease of bone treated with a five day course of oral tiludronate
}

\author{
J Y Reginster, M P Lecart, R Deroisy, D Ethgen, B Zegels, P Franchimont
}

\begin{abstract}
Chloro-4-phenyl thiomethylene bisphosphonate (tiludronate) is a new drug which can be used as an inhibitor of bone resorption. As it remains in bone for a long time, and as mineralisation defects have only been seen at doses much higher than those required to decrease osteoclastic activity, it could be given at high doses over a short period of time.
\end{abstract}

Eighteen patients with Paget's disease of bone were randomly allocated to three therapeutic groups receiving respectively 600,800 , and $1200 \mathrm{mg} /$ day tiludronate for five days. Serum alkaline phosphatase activity and the urinary hydroxyproline/creatinine ratio were quickly and drastically reduced in all three groups. A significant reduction of serum alkaline phosphatases and the hydroxyproline/ creatinine ratio was still present six months after the five day therapeutic course, reflecting a sustained activity of tiludronate even after stopping treatment. Dose dependent short and long term reductions of bone turnover rate were observed.

Biochemical assessment of haematological, renal, or hepatic tolerance did not show any toxicity of tiludronate. Fifty per cent of patients treated by a dose of $1200 \mathrm{mg} / \mathrm{day}$ reported gastrointestinal disturbances, however, making this dosage unsuitable for clinical practice.

(Ann Rheum Dis 1993; 52: 54-57)

Bisphosphonates inhibit bone resorption and have been reported to be effective in the treatment of Paget's disease of bone with a dose dependent response. ${ }^{1-7}$ Hydroxyethylidene bisphosphonate is the most widely available bisphosphonate and is extensively used in the treatment of Paget's disease of bone. ' Its use may lead, however, in particular with higher doses, to the inhibition of bone mineralisation..$^{89}$ This has led to the development of other bisphosphonates that may inhibit bone resorption without interference with the mineralisation of bone. Tiludronate (chloro-4-phenyl thiomethylene bisphosphonate) is a bisphosphonate now available for clinical testing. This bisphosphonate has been assayed in different models of bone resorption in animals ${ }^{10}$ and mineralisation defects were only seen at much higher doses than those required to decrease bone resorption. ${ }^{11}$ In Paget's disease of bone a six month course of tiludronate by mouth is able to reduce bone turnover without important side effects. $^{12} 13$ Furthermore, several studies have shown that treatment of Paget's disease of bone with short term courses of bisphosphonate may induce a sustained therapeutic effect. ${ }^{5-7} \mathrm{We}$ therefore, investigated the effect of three doses of tiludronate given by mouth for five days to patients with Paget's disease of bone.

\section{Patients and methods}

Eighteen patients presenting radiological and scintigraphic evidence of Paget's disease of bone in one (three patients) or more (15 patients) bones were included in this study after informed consent (table). All patients had active Paget's disease as judged by increased serum activity of alkaline phosphatases and urinary excretion of hydroxyproline. Before this study, 10 patients had never been treated for Paget's disease of bone, salmon calcitonin had been used to treat five patients (dose ranging from 50 IU intramuscularly three times a week to 200 IU/day nasally for three to six months), hydroxyethylidene bisphosphonate had been used for four patients ( $5 \mathrm{mg} / \mathrm{kg} /$ day for six months), and one patient had received aminohydroxypropylidene bisphosphonate $(250 \mathrm{mg} / \mathrm{kg} /$ day for six weeks). None of the patients had shown a normal value of serum alkaline phosphatases during previous treatments. A washout period of six months for calcitonin, three years for hydroxyethylidene bisphosphonate, and five years for aminohydroxypropylidene was respected before inclusion in the present study. All patients had relapsed as judged by a progressive increase in serum alkaline phosphatases of at least $20 \%$ from the lowest values reached with previous treatment.

Serum alkaline phosphatases were assessed by the method of Trayser and Seligson ${ }^{14}$ (normal range 40-135 IU/1). After an overnight fast and voiding the bladder, the urine produced over a two hour period was collected for measurement of hydroxyproline (Kit Hypronostikon Teknika, Organon, Oss-Boxtel, The Netherlands). The hydroxyproline concentration was expressed as a ratio to creatinine excretion $^{15}$ (normal range $0-24 \mathrm{mg} / \mathrm{g}$ ).

Patients were randomly assigned to three therapeutic groups, each containing six patients They were treated for five consecutive days receiving respectively $600 \mathrm{mg} /$ day (Gr600), $800 \mathrm{mg} /$ day (Gr800), and $1200 \mathrm{mg} /$ day (Gr1200) tiludronate by mouth. In the present study, we used a new formulation of tiludronate with a bioavailability twice as high $(4-8 \%$ of the ingested dose) than that used in our previous studies, ${ }^{13} 16$ for which the estimated bioavailability of tiludronate was between 2 and $4 \%$ 
of the ingested dose. Tiludronate was taken two hours before and after any food ingestion and only with $200 \mathrm{ml}$ of deionised water (Spa Reine). Serum alkaline phosphatases and the hydroxyproline/creatinine ratio were assessed before the first intake of tiludronate (day 1) and on each subsequent day of treatment (days 2, 3, 4, and 5). These parameters were also measured after the discontinuation of tiludronate at two (day 14), three (day 21), four (day 28), eight (day 56), 13 (day 90), 17 (day 120), 21 (day 150 ), and 25 (day 180) weeks after the beginning of the experimental procedure. Simultaneously, an analysis of biochemical parameters reflecting the haematological, renal, and hepatic functions and an exhaustive clinical evaluation were performed at each visit. All values of the hydroxyproline/creatinine ratio and serum alkaline phosphatases are expressed as mean (SEM) values and as a percentage of the values of serum alkaline phosphatases and the hydroxyproline/creatinine ratio measured at day 1 , considered as baseline ( $100 \%)$. In each group the statistical significance of the variations of serum alkaline phosphatases and the hydroxyproline/creatinine ratio at the different times of the study were appreciated by the mean of a two tailed Student's $t$ test whereas the variations of these parameters in the three groups were compared by a Zerbe curve-response analysis. ${ }^{17}$

\section{Results}

Three patients (two in Gr600 and one in Gr800) refused to come back for the biochemical investigations and were withdrawn from the statistical analysis. These three patients were personally contacted, however, and none had any side effects during or after tiludronate treatment. These three patients who dropped out left 15 patients: four in Gr600, five in Gr800, and six in Gr1200 (table).
At the beginning of the study there was no statistically significant difference between levels of serum alkaline phosphatases in the three groups. This allows us to compare changes in serum alkaline phosphatases in the three therapeutic groups during the study. This was not so for the hydroxyproline/creatinine ratio, which was significantly higher in Gr1200 patients compared with the Gr600 group. Levels of serum alkaline phosphatases were significantly reduced $(p<0.01)$ after two days of treatment in

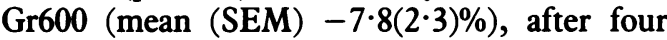
days in Gr800 (-29.3(13.8)\%), and after one day in Gr1200 (-13.1(4.4)\%). The maximum decrease in serum alkaline phosphatases was obtained at day 90 in $\operatorname{Gr600}(-30 \cdot 6(8 \cdot 2) \%)$, at day 90 in $\mathrm{Gr} 800(-45 \cdot 8(9 \cdot 3) \%)$, and at day 120 in Gr1200 $(-57 \cdot 8(3 \cdot 3 \%))$. At the end of the follow up (day 180), levels of serum alkaline phosphatases were still reduced in the three groups: $-25 \cdot 3(8.7) \%$ in Gr600 $(p<0.05)$, $-35 \cdot 0(17 \cdot 5) \%$ in Gr800 (NS), and $-57 \cdot 6(4 \cdot 1) \%$ in $\mathrm{Gr} 1200(\mathrm{p}<0.02)$ (fig 1). The analysis of curve-responses showed a statistically significant

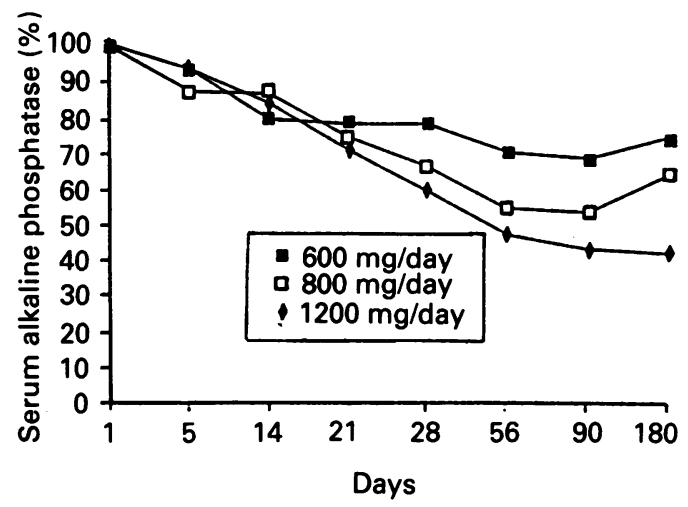

Figure 1 Mean decrease of serum alkaline phosphatases in the three groups during the five day course of treatment with tiludronate and six months of follow up. Dose group coverages are shown.

Baseline data for all patients in the study. Serum alkaline phosphatases and the hydroxyproline/creatinine ratio after three and six months are given.

\begin{tabular}{|c|c|c|c|c|c|c|c|c|c|c|}
\hline \multirow[t]{2}{*}{$\begin{array}{l}\text { Patient } \\
\text { No }\end{array}$} & \multirow[t]{2}{*}{$\begin{array}{l}\text { Age } \\
\text { (years) }\end{array}$} & \multirow[t]{2}{*}{ Sex } & \multirow[t]{2}{*}{$\begin{array}{l}\text { Previous } \\
\text { treatment* }\end{array}$} & \multirow[t]{2}{*}{$\begin{array}{l}\text { Bones } \\
\text { affectedt }\end{array}$} & \multicolumn{3}{|c|}{$\begin{array}{l}\text { Serum alkaline phosphatase } \\
(40-135 I U / l)\end{array}$} & \multicolumn{3}{|c|}{$\begin{array}{l}\text { Urinary hydroxyprolinel } \\
\text { creatinine ratio } \\
(0-24 \mathrm{mg} / \mathrm{g})\end{array}$} \\
\hline & & & & & Day 0 & Day 5 & Day 180 & Day 0 & Day 5 & Day 180 \\
\hline $\begin{array}{c}\text { Gr } 600 \\
1 \\
2 \\
3 \\
4 \\
\text { Mean } \\
\text { (SEM) }\end{array}$ & $\begin{array}{l}81 \\
57 \\
72 \\
69 \\
69 \cdot 7(4 \cdot 9)\end{array}$ & $\begin{array}{l}\mathbf{F} \\
\mathbf{M} \\
\mathbf{M} \\
\mathbf{F}\end{array}$ & $\begin{array}{l}\mathbf{A} \\
\mathbf{C}+\mathbf{B} \\
\mathbf{A} \\
\mathbf{A}+\mathbf{B}\end{array}$ & $\begin{array}{l}1 \\
1,2,4,7 \\
1,6,7,8 \\
1,7\end{array}$ & $\begin{array}{l}182 \\
564 \\
275 \\
785 \\
451(137)\end{array}$ & $\begin{array}{l}180 \\
516 \\
258 \\
666 \\
412(115)\end{array}$ & $\begin{array}{l}167 \\
489 \\
179 \\
435 \\
317(84)\end{array}$ & $\begin{array}{l}27 \cdot 1 \\
48 \cdot 4 \\
38 \cdot 4 \\
28 \\
\\
35(5)\end{array}$ & $\begin{array}{l}16 \cdot 1 \\
39 \cdot 1 \\
24 \cdot 5 \\
24 \cdot 7 \\
\\
26(4)\end{array}$ & $\begin{array}{l}26 \cdot 3 \\
40 \cdot 7 \\
25 \cdot 1 \\
22 \cdot 9 \\
\\
28(4)\end{array}$ \\
\hline $\begin{array}{c}\text { Gr } 800 \\
1 \\
2 \\
3 \\
4 \\
\text { Mean } \\
\text { (SEM) }\end{array}$ & $\begin{array}{l}80 \\
60 \\
53 \\
50 \\
66 \\
61 \cdot 8(5 \cdot 3)\end{array}$ & $\begin{array}{l}\mathbf{M} \\
\mathbf{M} \\
\mathbf{F} \\
\mathbf{F} \\
\mathbf{M}\end{array}$ & $\frac{\bar{A}}{\bar{B}}$ & $\begin{array}{l}4,5,8 \\
7 \\
10 \\
2,8,12 \\
1,2,4,6 \\
7,9,10\end{array}$ & $\begin{array}{l}316 \\
236 \\
519 \\
502 \\
847 \\
484(106)\end{array}$ & $\begin{array}{l}291 \\
208 \\
422 \\
441 \\
760 \\
424(94)\end{array}$ & $\begin{array}{l}172 \\
204 \\
115 \\
206 \\
1026 \\
344(171)\end{array}$ & $\begin{array}{c}26 \cdot 2 \\
27 \cdot 4 \\
86 \cdot 3 \\
46 \cdot 4 \\
111 \cdot 1 \\
59(17)\end{array}$ & $\begin{array}{c}43 \cdot 4 \\
18 \cdot 6 \\
30 \cdot 0 \\
41 \cdot 4 \\
124 \cdot 5 \\
52(19)\end{array}$ & $\begin{array}{l}17 \cdot 4 \\
19 \cdot 1 \\
30 \cdot 7 \\
16 \cdot 1 \\
81 \cdot 7 \\
33(12)\end{array}$ \\
\hline $\begin{array}{c}\text { Gr } 1200 \\
1 \\
2 \\
3 \\
4 \\
5 \\
6 \\
\text { Mean } \\
\text { (SEM) }\end{array}$ & $\begin{array}{l}72 \\
87 \\
67 \\
68 \\
63 \\
57 \\
69(4 \cdot 1)\end{array}$ & $\begin{array}{l}\mathbf{M} \\
\mathbf{F} \\
\mathbf{M} \\
\mathbf{F} \\
\mathbf{M} \\
\mathbf{F}\end{array}$ & $\begin{array}{l}z \\
z \\
z\end{array}$ & $\begin{array}{l}7,9 \\
1,7,9,10 \\
2,3,7,9 \\
1,2,4,7,9 \\
2,7,8,11 \\
1,2,7,9\end{array}$ & $\begin{array}{l}492 \\
675 \\
294 \\
381 \\
794 \\
905 \\
590(98)\end{array}$ & $\begin{array}{l}430 \\
611 \\
311 \\
404 \\
679 \\
805 \\
540(77)\end{array}$ & $\begin{array}{l}260 \\
386 \\
114 \\
134 \\
254 \\
349 \\
249(45)\end{array}$ & $\begin{array}{r}70 \cdot 9 \\
66 \cdot 2 \\
25 \cdot 3 \\
75 \cdot 8 \\
69 \cdot 3 \\
138 \cdot 9 \\
74 \cdot 4(15)\end{array}$ & $\begin{array}{l}35 \cdot 4 \\
51 \cdot 0 \\
16 \cdot 7 \\
34 \cdot 4 \\
30 \cdot 3 \\
87 \cdot 5 \\
43(10)\end{array}$ & $\begin{array}{l}71 \cdot 2 \\
71 \cdot 1 \\
9 \cdot 3 \\
40 \cdot 4 \\
33 \cdot 0 \\
73 \cdot 2 \\
50(11)\end{array}$ \\
\hline
\end{tabular}

*Previous treatment: $\mathrm{A}=$ hydroxyethylidene bisphosphonate; $\mathrm{B}=$ calcitonin; $\mathrm{C}=$ aminohydroxypropylidene. 


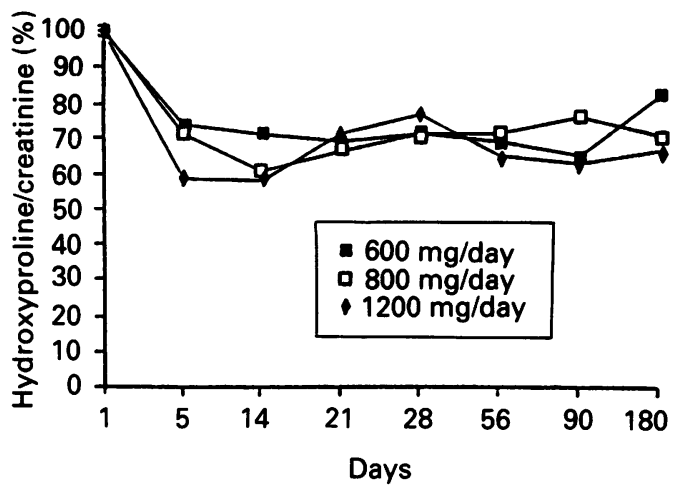

Figure 2 Mean decrease in the hydroxyproline/creatinine ratio in the three groups during the five day course of treatment with tiludronate and six months of follow up. Dose group averages are shown.

difference ( $p=0.0027)$ between the decrease of serum alkaline phosphatases in Gr600 and Gr1200 with the fluctuations of serum alkaline phosphatases in $\mathrm{Gr} 800$ following an intermediate pattern. The hydroxyproline/creatinine ratio was also quickly and drastically reduced in the three therapeutic groups: Gr600 $-7 \cdot 7(2 \cdot 3) \%$ after two days $(\mathrm{p}<0.02)$ with a maximum decrease of $-35 \cdot 4(6.2) \%$ at day $90(\mathrm{p}<0.01)$; Gr800 $-29 \cdot 3(13 \cdot 8) \%(\mathrm{p}<0.05)$ after four days with a maximum decrease of $-40 \cdot 2(11 \cdot 4) \%$ $(p<0.01)$ at day 90; and Gr1200-13.1(4.5)\% $(\mathrm{p}<0.02)$ after one day with a maximum decrease of $-40 \cdot 2(12 \cdot 0) \%(\mathrm{p}<0.01)$ at day 150 (fig 2). At the end of the study, the decrease in the hydroxyproline/creatinine ratio was still highly significant in $\operatorname{Gr600}(-17 \cdot 9(6 \cdot 5) \%)$ $(\mathrm{p}<0.02)$ and in Gr1200 $(-33.6(12 \cdot 2) \%)$ $(\mathrm{p}<0.02)$ whereas in $\mathrm{Gr} 800$ the decrease in the hydroxyproline/creatinine ratio did not reach statistical significance (-29.9 (19.9)\%) (NS). After the six month follow up period, only one patient $(7 \%)$ presented a complete biochemical remission, assessed by a normalisation of serum alkaline phosphatases and the hydroxyproline/ creatinine ratio, whereas five $(33 \%)$ other patients showed levels of serum alkaline phosphatases or a hydroxyproline/creatinine ratio within the normal range at that time (table).

No significant alteration of biochemical parameters reflecting haematological, renal, or hepatic metabolism were recorded. Clinically, tiludronate was perfectly tolerated in Gr800 patients, whereas one of six patients $(16 \%)$ in Gr600 and three of six patients (50\%) in Gr1200 presented mild gastrointestinal disturbances constituted by mild diarrhoea. This phenomenon did not lead to interruption of the treatment and spontaneously resolved after the end of the five day therapeutic course.

\section{Discussion}

Continuous administration of tiludronate for six months has previously been shown to reduce the bone turnover rate in Paget's disease of bone by approximately $40-50 \% .^{12} 13$ In this work a three to six times higher dose (considering a $100 \%$ increase in bioavailability for the new tiludronate formulation compared with that used in previous work) given for only five days was shown to induce a decrease in serum alkaline phosphatases varying from 30\% (600 $\mathrm{mg} /$ day) to $60 \%$ (1200 mg/day). Furthermore, six months after stopping this short term treatment the accumulation of tiludronate in bone and its subsequent release from the matrix gave a sustained therapeutic effect. In the groups receiving 800 or $1200 \mathrm{mg} /$ day, the mean decrease in serum alkaline phosphatases at that time (respectively 35 and $57 \%$ ) was almost identical to that described when low doses of tiludronate were given continuously for six months. This confirms the antiosteoclastic activity of tiludronate and its linkage to the bone matrix. These findings are in agreement with a previous report showing that, in healthy postmenopausal women, a six month course of tiludronate by mouth may counteract postmenopausal bone loss for at least one year by decreasing bone resorption. ${ }^{16}$

Short and long term inhibition of bone turnover rates by tiludronate follow a dose dependent pattern. Indeed, the maximum decrease in serum alkaline phosphatases and the reduction of this parameter reported at the end of the six month follow up are almost twice as high in patients treated with $1200 \mathrm{mg} /$ day tiludronate $(-57 \cdot 8(3 \cdot 3) \% ;-57 \cdot 6(4 \cdot 1) \%)$ than in subjects who received $600 \mathrm{mg} /$ day $(-30.6$ $(8 \cdot 2) \% ;-25 \cdot 3(8 \cdot 7) \%)$, whereas patients with Paget's disease treated by a daily dose of $800 \mathrm{mg}$ follow an intermediate pattern $(-45 \cdot 8(9 \cdot 3) \%$; $-35 \cdot 0(17 \cdot 5) \%)$.

Even with the higher dose of tiludronate, however, the percentage of patients with complete and sustained biochemical remission remains low compared with those treated with other bisphosphonates such as aminohydroxypropylidene, dichloromethylene bisphosphonate, and aminohexane bisphosphonate ${ }^{518} 19$ by mouth for either a short or long period of time. The mean decrease of serum alkaline phosphatases and the hydroxyproline/creatinine ratio reported with tiludronate is relatively close to that obtained during treatment with calcitonin or hydroxyethylidene bisphosphonate. ${ }^{1}$ The absence of fractures in lytic areas of weightbearing bones and the absence of an increase in bone pain in the same areas, as described for hydroxyethylidene bisphosphonate during treatment, might be considered as a relative indication of the absence of impairment of mineralisation when using these doses of tiludronate. ${ }^{1}$

No limiting side effects occurred in patients in Gr600 and Gr800. In Gr1200, however, the high rate $(50 \%)$ of gastrointestinal disturbances, even if they spontaneously resolved after the end of the treatment, is likely to make this dose unsuitable for daily practice. Gastrointestinal side effects are also a common feature of treatment with other bisphosphonates. Nausea and irritation of the gastric mucosa are important side effects of treatment with aminohydroxypropylidene by mouth which, at a dose of 600 $\mathrm{mg} /$ day, induces gastritis and oesophagitis in up to $30 \%$ of patients. ${ }^{20}$ With hydroxyethylidene bisphosphonate and dichloromethylene bisphosphonate, slight gastric discomfort and diarrhoea are reported as possible side effects. ${ }^{121}$ 
In conclusion, treatment with tiludronate by mouth at high doses for only five days is followed by a clinical and biochemical response which is sustained for several months. There is a dose dependent reduction of bone turnover rate. Gastrointestinal disturbances, however, make $1200 \mathrm{mg} /$ day an unsuitable dose for clinical daily practice. The biochemical reduction of disease activity, persisting for months after the end of treatment, confirms the potential usefulness of tiludronate by mouth as an intermittent treatment for metabolic bone disorders characterised by an excess of bone resorption.

1 Kanis J A, Gray R E. Long-term follow-up observations on treatment in Paget's disease of bone. Clin Orthop 1987; 217: 99-125.

2 Alexandre C, Meunier P J, Edouard C, Khairi R A, Johnston C C. Effects of ethane-1, hydroxy-1, 1-diphosphonate ( $5 \mathrm{mg} / \mathrm{kg} /$ day dose) on quantitative bone histology in Paget's disease of bone. Metab Bone Dis Relat Res 1981; 4-5: $309-16$.

3 Frijlink $W$ B, te Velde J, Bijvoet $O$ L M, Heynen G. Treatment of Paget's disease of bone with (3-amino-1Treatment of Paget's disease of bone with (3-amino-1-
hydroxypropilidene-1, 1-bisphosphonate) (APD). Lancet hydroxypropilidene-1,
1979; i: 799-803.

4 Meunier P J, Chapuy M C, Alexandre C, et al. Effects of disodium dichloromethylene diphosphonate (C12MDP) on Paget's disease of bone. Lancet 1979; ii: 489.

5 Thiebaut D, Jaeger P, Burckhardt P. Paget's disease of bone treated in five days with AHPrBP (APD) per os. 7 Bone Miner Res 1987; 2: 45-52.

6 O'Doherty D P, Bisckerstaff D R, McCloskey E V, et al. Treatment of Paget's disease of bone with aminohydroxyTreatment of Paget's disease of bone with aminohydroxy-
butylidene bisphosphonate. $\mathcal{F}$ Bone Miner Res 1990; 5: butylidene

7 Adami S, Salvagno G, Guarrera G, et al. Treatment of Paget's disease of bone with intravenous 4-amino-1-hydroxybutylidene-1, 1-bisphosphonate. Calcif Tissue Int 1986; 39: 226-9.

8 Gibbs J C, Aron J E, Peacock M. Osteomalacia in Paget's disease treated with short term, high dose sodium etidronate BMF 1986; 292: 1227-9.

9 Kanis J A, Urwin G, Gray R E, et al. Effects of intravenous etidronate disodium on skeletal and calcium metabolism. Am F Med 1987; 82: 55-70.

10 Emonds-Alt X, Breliere J C, Roncucci R. Effects of 1 hydroxyethilidene-1, l-bisphosphonate and (chloro-4hydroxyethilidene-1, l-bisphosphonate and (chloro-4the mononuclear cell factor-mediated release of neutral the mononuclear cell factor-mediated release of neutral proteinases by articular chrondrocyte
Biochem Pharmacol 1985; 34: 4043-9.

11 Charhon S, Meunier P, Ethgen D, Lacheretz F, Breliere J C Roncucci $R$. Histomorphometric analysis of bone biopsies of baboons treated with "SR 41319 B" a new diphosphonate. Calcif Tissue Int 1985; 38: S33.

12 Audran M, Clochon P, Ethgen D, Mazieres B, Renier J C. Treatment of Paget's disease of bone with (4-chlorophenyl) thiomethylene bisphosphonate. Clin Rheumatol 1989; 8: 71-9.

13 Reginster J Y, Jeugmans-Huynen A M, Albert A, et al. Biological and clinical assessment of a new bisphosphonate (chloro-4-phenyl) thiomethylene bisphosphonate, in the treatment of Paget's disease of bone. Bone 1988; 9: 349-54

14 Trayser K A, Seligson D. A new kinetic mode for enzym analysis suitable for automation. Clin Chem 1969; 15: 452.

15 Nordin B E C. Diagnostic procedures in disorders of calcium metabolism. Clin Endocrinol 1978; 8: 55-67.

16 Reginster J Y, Lecart M P, Deroisy R, et al. Prevention of postmenopausal bone loss by tiludronate. Lancet 1989; ii: 1469-71.

17 Zerbe G O. Randomization analysis of the completely randomized design extends to growth and response curves. Fournal

18 Atkins R M, Yates A J T, Gray R E S, et al. Aminohexane diphosphonate in the treatment of Paget's disease of bone. f Bone Miner Res 1987; 2: 273-9.

19 Chapuy M C, Charhon S A, Meunier P J. Sustained biochemical effects of short treatment of Paget's disease of bone with dichloromethylene diphosphonate. Metab Bone Dis Relat Res 1983; 4: 325-8.

20 Harinck H I J, Bijvoet O L M, Blaksman H J, DahlinghausNienhuys $\mathbf{P}$ J. Efficacious management with aminobisphosphonate (APD) in Paget's disease of bone. Clin Orthop Rel Res 1987; 217: 79-98.

21 Reginster J Y, Gritten C, Diverse P, et al. Traitement de la maladie de Paget par l'Etidronate disodique (EHDP) à faible dose: apparition de leucopénies transitoires réversibles suspectes. Rev Rhum Mal Osteoartic 1985; 52: 145-50. 